\title{
Viscoelastic properties of doped-ceria under reduced oxygen partial pressure
}

Teocoli, Francesca; Esposito, Vincenzo

\section{Published in:}

Scripta Materialia

Link to article, DOI:

10.1016/j.scriptamat.2013.11.027

Publication date:

2014

Link back to DTU Orbit

Citation (APA):

Teocoli, F., \& Esposito, V. (2014). Viscoelastic properties of doped-ceria under reduced oxygen partial pressure. Scripta Materialia, 75, 82-85. https://doi.org/10.1016/j.scriptamat.2013.11.027

\section{General rights}

Copyright and moral rights for the publications made accessible in the public portal are retained by the authors and/or other copyright owners and it is a condition of accessing publications that users recognise and abide by the legal requirements associated with these rights.

- Users may download and print one copy of any publication from the public portal for the purpose of private study or research.

- You may not further distribute the material or use it for any profit-making activity or commercial gain

- You may freely distribute the URL identifying the publication in the public portal

If you believe that this document breaches copyright please contact us providing details, and we will remove access to the work immediately and investigate your claim 


\section{Accepted Manuscript}

Viscoelastic properties of doped-ceria under reduced oxygen partial pressure

Francesca Teocoli, Vincenzo Esposito

PII:

S1359-6462(13)00594-0

DOI: http://dx.doi.org/10.1016/j.scriptamat.2013.11.027

Reference: SMM 10126

To appear in:

Scripta Materialia

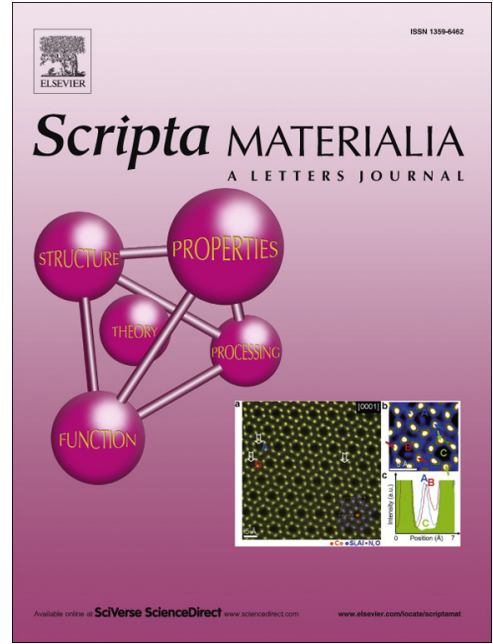

Please cite this article as: F. Teocoli, V. Esposito, Viscoelastic properties of doped-ceria under reduced oxygen partial pressure, Scripta Materialia (2013), doi: http://dx.doi.org/10.1016/j.scriptamat.2013.11.027

This is a PDF file of an unedited manuscript that has been accepted for publication. As a service to our customers we are providing this early version of the manuscript. The manuscript will undergo copyediting, typesetting, and review of the resulting proof before it is published in its final form. Please note that during the production process errors may be discovered which could affect the content, and all legal disclaimers that apply to the journal pertain. 


\title{
Viscoelastic properties of doped-ceria under reduced oxygen partial pressure
}

\section{Francesca Teocoli and Vincenzo Esposito \\ Department of Energy Conversion and Storage, Technical University of Denmark (DTU), Frederiksborgvej 399, DK-4000 Roskilde, Denmark}

\begin{abstract}
The viscoelastic properties of gadolinium-doped ceria (CGO) powder compacts are characterized during sintering and cooling under reduced oxygen partial pressure and compared with conventional sintering in air. Highly defective doped ceria in reducing conditions shows peculiar viscoelastic properties due to fast mass diffusion phenomena activated at low temperatures by $\mathrm{Ce}^{4+}$ to $\mathrm{Ce}^{3+}$ reduction. Particularly, the viscous behavior is affected by dramatic microstructural changes, fast grain growth and densification, which are rapidly completed in the last stage of sintering.
\end{abstract}

Keywords: Ceramics; Sintering; Dynamic mechanical analysis; Powder consolidation

Acceptor doped ceria, where the dopant is a rare earth metal, has received considerable attention as solid electrolyte candidate for solid oxide fuel cells (SOFCs), and solid oxide electrolysis cells (SOECs), as membrane for oxygen separation applications, and as catalytic support for thermochemical $\mathrm{H}_{2} \mathrm{O} / \mathrm{CO}_{2}$ splitting by solar concentration. [1-4] In particular, gadolinium-doped ceria (CGO) presents excellent high oxide ion conductivity and chemical stability under diverse cell operating conditions. [5] Sintering of ceria-oxides is essential in order to obtain high performing dense materials since residual porosity in electrolyte films with reduced thickness can be detrimental for the mechanical properties, gas tightness and conductivity. [6] Furthermore, ceria components operate at high temperatures and often under reduced oxygen pressure $\left(\mathrm{pO}_{2}\right)$, being subject to a severe chemical expansion. All these conditions, in addition to possible geometrical constraint in the co-sintering of multi-layered structures, can influence the mechanical properties leading to failure or ineffectiveness of the related densification mechanisms. [7, 8] Therefore, knowledge of thermo-mechanical properties such as uniaxial viscosity, and how they evolve during the thermal process and under different atmospheres, is essential in order to obtain microstructural and structural stability. [9] 
In a recent study, one author of the present work reported that CGO powders of diverse morphologies, sintered under low oxygen partial pressure $\left(\mathrm{pO}_{2}<10^{-12} \mathrm{~atm}\right)$, show fast mass diffusion mechanisms which lead to a full densification and fast grain growth at low temperatures. [10] Such phenomena are activated by reduction of $\mathrm{Ce}^{4+}$ to $\mathrm{Ce}^{3+}$ which, compared to the oxidized form, increases the mass diffusion coefficient by several orders of magnitude. Consequently, dramatic changes in the microstructure are observed and changes in the thermo-mechanical properties of the materials during processing and operation are also expected.

In this study, the viscoelastic properties of gadolinium-doped ceria (CGO, or GDC10) were investigated during sintering under reduced oxygen partial pressure, and compared with conventional sintering in air. A screening of the thermo-mechanical properties during cooling was also carried out. This is crucial especially to characterize the transition from the viscoelastic to the pure elastic regime $(\mathrm{V}-\mathrm{E})$ in the reduced materials, where the dramatic volume changes due to chemical expansion and contraction can easily lead to catastrophic failure in the elastic continuum. [10]

Commercial CGO (10 mol.\% Gd, $\mathrm{Ce}_{0.9} \mathrm{Gd}_{0.1} \mathrm{O}_{1.95-\delta}$ : GDC10) powder from Rhodia (France) with specific surface areas of $\sim 3 \mathrm{~m}^{2} / \mathrm{g}$, named LSA (low surface area), was used to realize rectangular dry pressed $15 \times 5 \mathrm{~mm}$ rectangular pellets, with a thickness of $0.5 \mathrm{~mm}$. Green density was around $40 \%$.

The uniaxial viscosity of glass and ceramic materials is usually measured by several techniques, such as sinter-forging technique, cyclic loading dilatometry, and bending creep. [5, 11-13] We carried out a three-point bending experiment, applying a superimposed 8-min squared cyclic loading profile. The maximum load was $4 \mathrm{mN}$. The method was performed by a high precision thermo-mechanical analyzer (TMA, 402 F1 Hyperion, Netzsch, Germany) which operates at high temperatures (up to $1550{ }^{\circ} \mathrm{C}$ ) applying a wide range of dynamic loads. At low temperature, the deflection values for both samples were in the range of $5 \mathrm{~nm}$. Thermo-mechanical analysis measures were carried out with an accuracy of +/- $0.125 \mathrm{~nm}$ and multiple tests were conducted in order to assure the repeatability of results. Temperature sweep, from room temperature to $1450{ }^{\circ} \mathrm{C}$ and cooling back to room temperature, were performed in a flow of $50 \mathrm{ml} / \mathrm{min}$ in air $\left(p \mathrm{O}_{2}=0.2\right.$ atm) or in dry $9 \% \mathrm{H}_{2}-\mathrm{N}_{2}\left(10^{-24}<p \mathrm{O}_{2}<10^{-12}\right.$ atm). The heating rate was $1^{\circ} \mathrm{C} / \mathrm{min}$, there was short dwell time of around 1 hour at the maximum temperature, and the cooling rate was $2^{\circ} \mathrm{C} / \mathrm{min}$. After the entire thermal cycle, scanning electron microscopy (SEM; Hitachi TM1000, Tokyo, Japan and Carl Zeiss field emission microscope (SUPRA 35) for high resolution imaging) was used to compare the final microstructure of the samples sintered in air and in 
reducing conditions. Further experimental details on pellets fabrication and oxygen partial pressure determination are reported elsewhere. [10]

Sintering ceramic materials are generally defined as viscoelastic, and their mechanical behavior can be modeled with a combination of elastic springs and viscous dashpots. [14, 15] However, R. K. Bordia and G. W. Scherer [16] argued that sintering ceramic compacts cannot be compared to a Kelvin-Voigt element, where the strain is recovered anelastically, and this is not physically reasonable for a body undergoing densification. Therefore, the mechanical response of a sintering body can be compared to that of a Maxwell element. (figure 1a). [12] In this case, the strain response of the elastic body follows the stress profile; conversely, the permanent deformation is attributed to the viscous element only. In figure $1 \mathbf{b}$ the displacements and the displacement rates for CGO treated in air and in $9 \% \mathrm{H}_{2}-\mathrm{N}_{2}$ are plotted in the temperature range from $400{ }^{\circ} \mathrm{C}$ to $500{ }^{\circ} \mathrm{C}$. The imposed cyclic loading profile caused displacements due to strains in the samples; the displacement changes were proportional to the load stress applied, increasing and decreasing instantaneously upon loading/unloading. In this range both samples were largely elastic with the viscous element contribution considered to be negligible.

Figure 1c shows the displacements and the displacement rates for $\mathrm{CGO}$ sintered in air and in $9 \% \mathrm{H}_{2-}$ $\mathrm{N}_{2}$, plotted in the temperature range from $1200{ }^{\circ} \mathrm{C}$ to $1300{ }^{\circ} \mathrm{C}$. Both samples exhibited very distinctive viscous behaviors if compared with the Maxwell model (figure 1a). The displacement curves of both samples did not follow the cyclic loading profile as in the low temperature regime. (figure 1b) Displacement responses to the applied load showed the typical increase with time and temperature, due to the viscous contribution to the total deformation. Therefore, in agreement with the Maxwell model, the displacement rates are proportional to the applied load stress and for temperatures above $1200{ }^{\circ} \mathrm{C}$ the viscous component becomes dominant. Diffusion phenomena, leading to sintering, occur at high temperatures. Particularly in ceria, mass diffusion strongly depends on oxygen defect concentration and temperature. [17] $\mathrm{CGO}$ in $9 \% \mathrm{H}_{2}-\mathrm{N}_{2}$ at $1200{ }^{\circ} \mathrm{C}$ to $300{ }^{\circ} \mathrm{C}\left(10^{-12}<p O_{2}<10^{-18} \mathrm{~atm}\right)$ is highly defective, with large oxygen sub-stoichiometry and large concentration of $\mathrm{Ce}^{+3}$ cations. $\mathrm{CGO}$ in air possesses an oxygen vacancy concentration which is constant and depends mainly on the dopant concentration. Such different chemical conditions can substantially change the cation diffusion in the material and thus the overall mass diffusion phenomena in the samples during sintering [10]. The TMA indicates consistently that the displacement rate curves largely depend on the $\mathrm{pO}_{2}$. The TMA measurements reported in figure 1c and 1d show that the viscous component becomes evident with increasing 
temperature. The narrow temperature range at which the viscous plastic deformation became larger than the elastic deformation in one load cycle is here defined as the elastic-to-viscous transition (E-V). Since such a transition can be affected by several experimental factors such as the heating rate, the nature of the applied load, and resolution of the measurement, it is here estimated qualitatively, for a range of temperatures, and in a comparative approach for the two different atmospheres. In particular, figure 1d (inset on the left) shows the displacement rate for CGO characterized in air and in $9 \% \mathrm{H}_{2}-\mathrm{N}_{2}$ for temperature above $800{ }^{\circ} \mathrm{C}$, where, in the limits of the experimental error, it was possible to identify a narrow temperatures range between $840-850{ }^{\circ} \mathrm{C}$ for the $\mathrm{E}-\mathrm{V}$ transition. In the same way, for CGO treated in air, the E-V transition was found in the range of temperatures between 1000 and $1025{ }^{\circ} \mathrm{C}$ (figure 1d, inset on the right). Such difference in the viscous-elastic behavior is remarkable and it is also consistent with the observations on the densification previously reported. [10, 18]

To determine the uniaxial viscosity in such conditions, the material needs to exhibit a linear viscous behavior. As reported by R. K. Bordia and G. W. Scherer [16], since densifying ceramic materials are modeled as a linear viscous continuum and due to the analogy between linear viscous and linear elastic deformation mechanisms, it is possible to simply replace Young's modulus by the uniaxial viscosity, $\mu$, and the displacement, $\delta$, by the displacement rate, $\dot{\delta}$, in the general displacement equation of the linear elastic theory of beam. [13] In the cyclic loading bending experiment, a changing load $\mathrm{P}$, is applied at the center of the beam; the maximum displacement load, $\delta$ can be expressed as

$\underset{\text { Load }}{\delta \max }=\frac{5 \rho g L^{4}}{32 E h^{2}}+\frac{P L^{3}}{4 E w h^{3}}$

where $w$ is the width of the specimen.

Therefore viscosity is calculated for the applied load as

$\mu_{\text {Load }}=\frac{h w\left(5 \rho g L^{4}\right)+8 P L^{3}}{32 \dot{\delta} h^{3} w}$

where the viscosity is inversely related to the displacement rate.

In this work, uniaxial viscosities for CGO treated in air and under reducing conditions were calculated by equation (2), and figure 2a reports the viscosity values above the onset temperatures where the elastic-to-viscous transition appeared. In the initial stage of sintering, the viscosity for both samples was in the range of $10^{2} \mathrm{GPa} \cdot \mathrm{s}$. However, the CGO sample sintered under reducing conditions showed 
slightly higher displacement rate above $850{ }^{\circ} \mathrm{C}$ with an abrupt viscosity drop at around $900{ }^{\circ} \mathrm{C}$ and a minimum at around $1100{ }^{\circ} \mathrm{C}$. Conversely, CGO in air shows a slow transition from the elastic regime ( $\mathrm{T}<900{ }^{\circ} \mathrm{C}$, see also figure $1 \mathbf{d}$ inset on the left) and the dominant viscous behavior with a minimum viscosity at around $1250{ }^{\circ} \mathrm{C}$. The different thermo-mechanical behaviors can be attributed to different sintering mass diffusion mechanisms at the grain boundaries, and also to an incipient diversification of the microstructure in the two different sintering conditions. During sintering, the viscosity of ceramic materials depends strongly on temperature and microstructural features (i.e. relative density, grain size and porosity). [13, 14, 16, 19] Particularly, as also reported by Bollina and German [20], uniaxial viscosity decreases with the increase of mass diffusion at the preliminary and intermediate stages of the sintering. Viscosities decreased to around $40 \mathrm{GPa} \cdot \mathrm{s}$ and to $20 \mathrm{GPa} \cdot \mathrm{s}$ for CGO sintered in air and in $9 \%$ $\mathrm{H}_{2}-\mathrm{N}_{2}$, respectively, and it is worth noting that the minimum of viscosity for CGO sintered both in air and in reducing conditions corresponded with the maximum sintering activity reported in ref. 10. However, the different thermo-mechanical properties between CGO treated in air and under reducing conditions was still evident at higher temperatures in the later stage of the sintering, where high density and grain growth can influence the viscosity. Figure 2a shows that for temperatures above $1100{ }^{\circ} \mathrm{C}$ and $1250{ }^{\circ} \mathrm{C}$ for $\mathrm{CGO}$ treated in $9 \% \mathrm{H}_{2}-\mathrm{N}_{2}$ and in air, respectively, viscosity starts increasing and keeps increasing for higher temperatures towards the final steps of the sintering. The viscosities, calculated in both atmospheres, increased due to a change of the microstructure in the samples, from porous body to dense continuum. At the end of the heating at $1450{ }^{\circ} \mathrm{C}$, the $\mathrm{CGO}$ treated under reducing conditions reached a constant value higher than for the sample in air. Such conditions can be attributed to higher density and larger grains for the reduced sample. [5, 13]

The different effects of the densification in air and under reducing conditions on the uniaxial viscosities are more evident in figure $\mathbf{2 b}$. Isothermal sintering in $9 \% \mathrm{H}_{2}-\mathrm{N}_{2}$ at $1450^{\circ} \mathrm{C}$, despite the short duration of the dwell $(\sim 1 \mathrm{~h})$, led to an increase of the uniaxial viscosity; the CGO treated in $9 \% \mathrm{H}_{2}-\mathrm{N}_{2}$ exhibited a viscosity one order of magnitude larger than the same material treated in air, where, conversely, the viscosity remained constant. Moreover, when the relative density increases above 95\%, the density and grain growth are more dominating factors in increasing viscosity than the temperature. [13] (figure 2binset)

The effects of heat treatment in air and in $9 \% \mathrm{H}_{2}-\mathrm{N}_{2}$ at $1450^{\circ} \mathrm{C}$ are reported respectively in figure 3 (a and b). This includes the effect of the holding time at the maximum sintering temperature and the 
cooling. The relative densities of both samples after the sintering cycle were estimated by deduction of porosity. The relative density for CGO in air, after the entire thermal cycle, was around 94\%. (figure 3a-inset) Conversely, in reducing conditions the ceria-based material reached a higher densification, the relative density was estimated above $98 \%$. (figure $3 \mathbf{b}$-inset) The results shown in figure $\mathbf{3}$ (a and b) and the microstructures of the fracture sections reported in figure $\mathbf{3}$ (a and b) are consistent with the experimental observations that grain growth in air is limited due to solute drag phenomena at the grain boundary $[10,17,21]$, while the effect of a thermal treatment in $9 \% \mathrm{H}_{2}-\mathrm{N}_{2}$ on CGO pellets made of the same LSA powder, resulted in a fast grain growth, from $\sim 250 \mathrm{~nm}$ to $\sim 10 \mu \mathrm{m}$ and in a very little residual porosity.[10]

In figure 4, the displacements and displacement rates are plotted as a function of temperature during cooling $\left(2{ }^{\circ} \mathrm{C} / \mathrm{min}\right)$ for $\mathrm{CGO}$ both in air and in $9 \% \mathrm{H}_{2}-\mathrm{N}_{2}$. Between $1450-1350{ }^{\circ} \mathrm{C}$ the viscous-to-elastic transition (V-E transition) occurred for CGO cooled under reducing conditions. According to the Maxwell model (figure 1a), at $1450^{\circ} \mathrm{C}$, the displacement rate exhibited the typical profile of elastic response to the applied stress. In reducing atmosphere the V-E transition happened in the very earlystage of the cooling, confirming a strong influence of the microstructural factor. As predicted, the viscous-to-elastic transition for $\mathrm{CGO}$ cooled in air occurred for temperature lower than that in $9 \% \mathrm{H}_{2}$ $\mathrm{N}_{2}$. In particular, the transition was found in the limited range between $1350-1250{ }^{\circ} \mathrm{C}$. Different V-E transition temperatures with respect to the heating are due to the resulting microstructures obtained after sintering and, although mainly depending on microstructural features, viscoelastic properties also change with the temperature. $[13,14,16,19]$ At the onset of cooling, the substantial grain growth and high density obtained during isothermal sintering affected the V-E transition of CGO treated in reducing conditions. Conversely, for CGO cooled in air, where microstructural features changed during the isothermal sintering, the V-E transition was dependent mainly on the temperature.

In conclusion, CGO sintered in reducing conditions shows different viscous behavior with respect to the material sintered in air. This is the result of 1) thermally activated enhanced mass diffusion mechanisms during the early stage of the sintering, and 2) consequent dramatic microstructural changes (fast grain growth and densification) which are rapidly completed in the last stage of the sintering. Although such a dependence of the viscosity on the temperature and microstructure is established for CGO both treated in air and in $9 \% \mathrm{H}_{2}-\mathrm{N}_{2}$, in reducing conditions the transition occurs more rapidly 
leading to an abrupt change in thermo-mechanical properties. Moreover, despite the cation diffusion coefficients being greater in the reducing conditions, the higher viscosity in the sample sintered in $9 \%$ $\mathrm{H}_{2}-\mathrm{N}_{2}$ can be attributed to the coarser microstructure that develops. Consequently, the viscous-toelastic transition also occurs at much lower temperature for the CGO powder compacts cooled in air.

The authors would to acknowledge the EUDP (Danish Energy Agency) project 64012-0225 "SOFC accelerated", for sponsoring this research work. The authors are grateful to Christopher R. Graves for his help with the proofreading.

\section{Figure captions}

Figure 1. a) Maxwell model and schematic representations of the stress-strain response for elastic, viscous and viscoelastic materials. b) Displacement and displacement rate plotted for CGO in air and $9 \% \mathrm{H}_{2}-\mathrm{N}_{2}$ during heating between 400 and $500{ }^{\circ} \mathrm{C}$. c) Viscous response showed by displacement and displacement rate curves during sintering for heating from 1200 to $1300{ }^{\circ} \mathrm{C}$. d) Elastic-to-viscous transitions (E-V) during sintering for $\mathrm{CGO}$ in air and in $\mathrm{H}_{2} / \mathrm{N}_{2}$ plotted as a function of temperature.

Figure 2. a) Uniaxial viscosity as a function of temperature for CGO sintered in air and in $9 \% \mathrm{H}_{2}-\mathrm{N}_{2}$. b) Uniaxial viscosity as a function of time for CGO in air and under reducing conditions. In the inset, the uniaxial viscosities as functions of relative densities.

Figure 3. SEM images of microstructural features of CGO sintered at $1450^{\circ} \mathrm{C}$ (a) in air, and (b) under reducing conditions on fractured and polished (inset) sections.

Figure 4. Viscous-to-elastic transitions (V-E) showed by displacement and displacement rate plotted for CGO in air and $9 \% \mathrm{H}_{2}-\mathrm{N}_{2}$ during the early-stage of cooling.

\section{References}

[1] A.J.Jacobson, Chem. Mater., 2010, 22, p. 660

[2] M. Gödickemeier, and L.J. Gauckler, J. Electrochem. Soc., 1998, 145, p. 414

[3] H. Takamura, et al., Alloy Compd., 2006, 408-412, p. 1084

[4] W.C. Chueh, C. Falter, M. Abbott, D. Scipio, P. Furler, S.M Haile., et al., Science 2010, 330, p. 1797 
[5] J. Chang, et al., J. Eur. Ceram. Soc. 2007, 27, p. 3127

[6] H. Inaba, T. Nakajima, and H. Tagawa, Solid State Ionics 1998, 106, p. 263

[7] M. Qiu, J. Feng, Y. Fan, N. Xu, J. Mater. Sci., 2009, 44, p.689

[8] T. J. Garino, and H. K. Bowen, J.Am.Ceram.Soc. 1990, 73, p. 251

[9] A. Mohanram, G.L. Messing, and D.J. Green, J.Am.Ceram.Soc. 2005, 88, p. 2681

[10] V. Esposito, et al., Acta Mater., 2013, 61, p. 6290

[11] M.N. Rahaman, L.C. De Jonghe, G.W. Scherer, and R.R. Brook, J. Am. Ceram. Soc., 1987, 70, p. 766

[12] P.Z. Cai, G.L. Messing, and D.J. Green, J. Am. Ceram. Soc., 1997, 80, p.445

[13] S.H. Lee, G.L. Messing, and D.J. Green, J. Am. Ceram. Soc., 2003, 86, p.877

[14] Hsueh C. H., Evans A. G., Cannon R. M., and Brook R. J., Viscoelastic, Acta Metall., 1986, 34 , p. 927

[15] R.K. Bordia, and R. Raj, J. Am. Ceram. Soc., 1988, 71, p. 302

[16] R.K. Bordiá, and G.W. Scherer, Acta Metall., 1988, 36, p. 2393 and p. 2399

[17] Chen P.-L., and Chen I.-W., J. Am. Ceram. Soc., 1994, 77, p. 2289

[18] Z. He, et al., Acta Mater., 2010, 58, p. 3860

[19] E. Olevsky, Mater. Sci. Eng., 1998, R23, p. 41

[20] R. Bollina, and R.M. German, In situ evaluation of viscosity during sintering of boron doped stainless steel using bending beam technique. Proceedings of World PM2004 - Vienna, Austria, published by EPMA, Shrewsbury, United Kingdom, 2004

[21] M. Kuhn, S.R. Bishop, J.L.M. Rupp, H.L. Acta Mater., 2013, 61, p. 4277 
a)

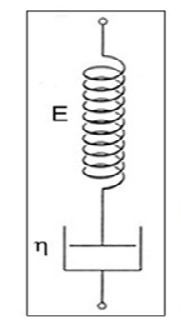

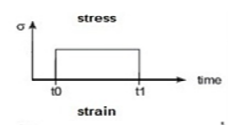

a)

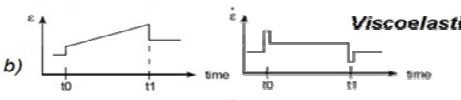

${ }^{\varepsilon} \uparrow \quad$ Viscous
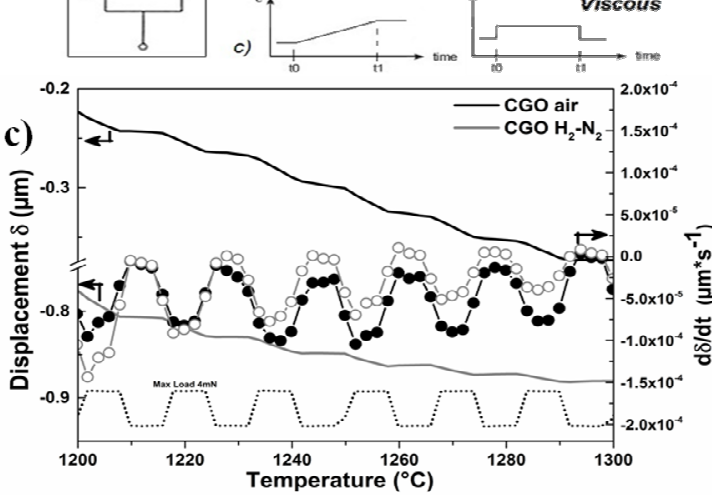

b)

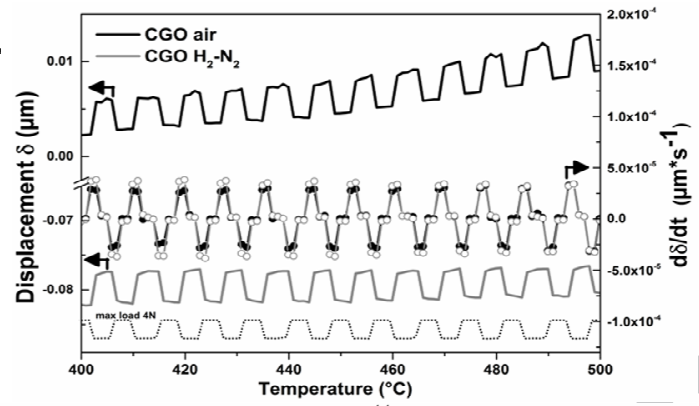

d)

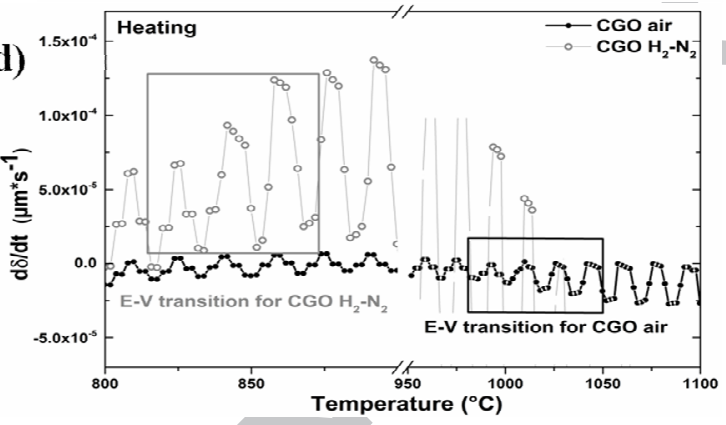



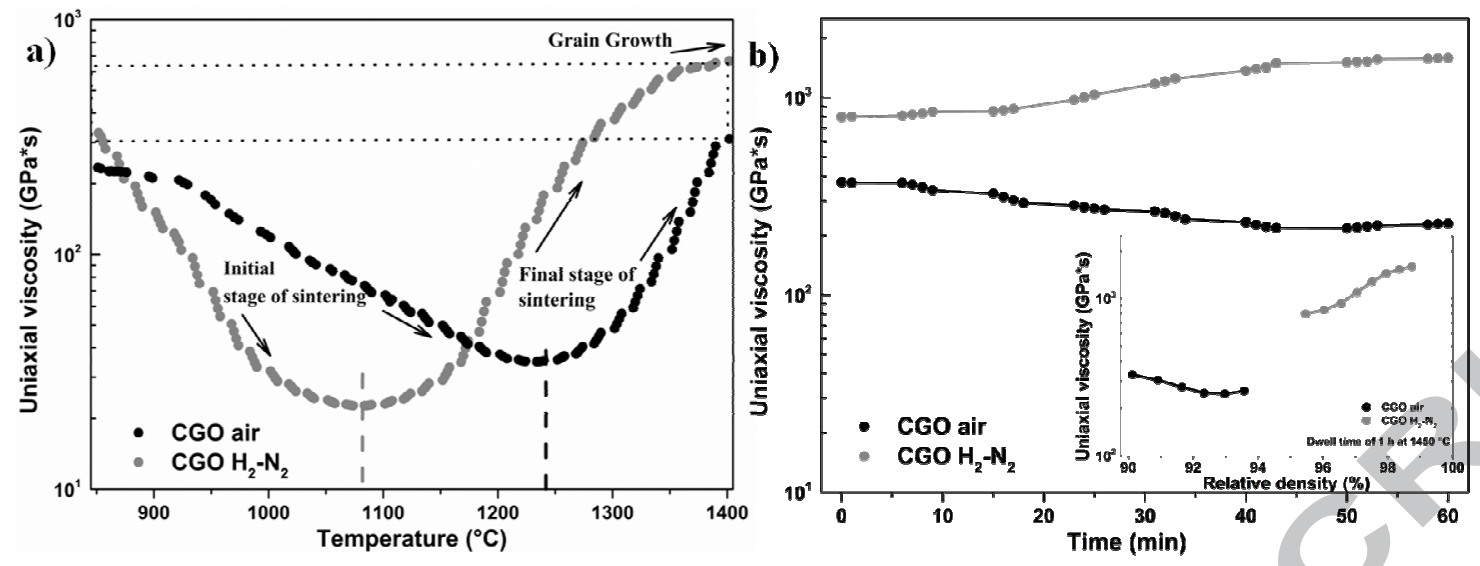


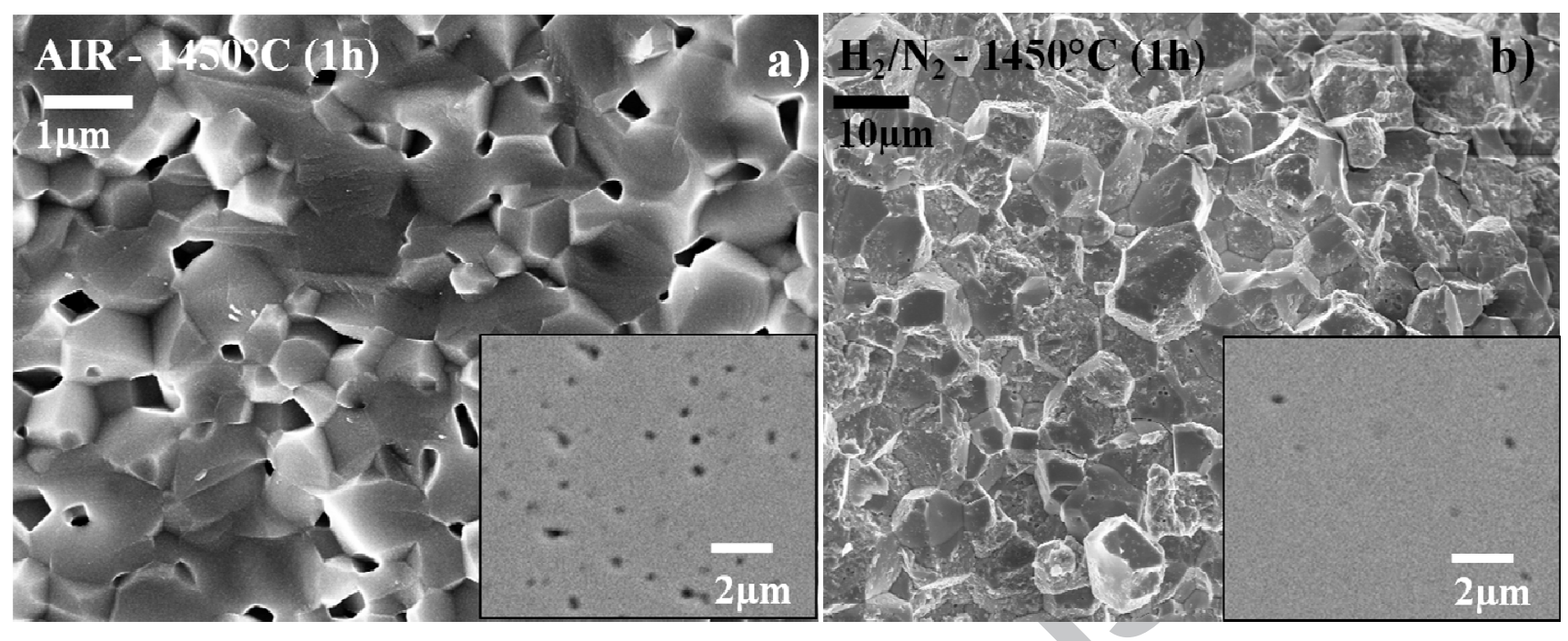




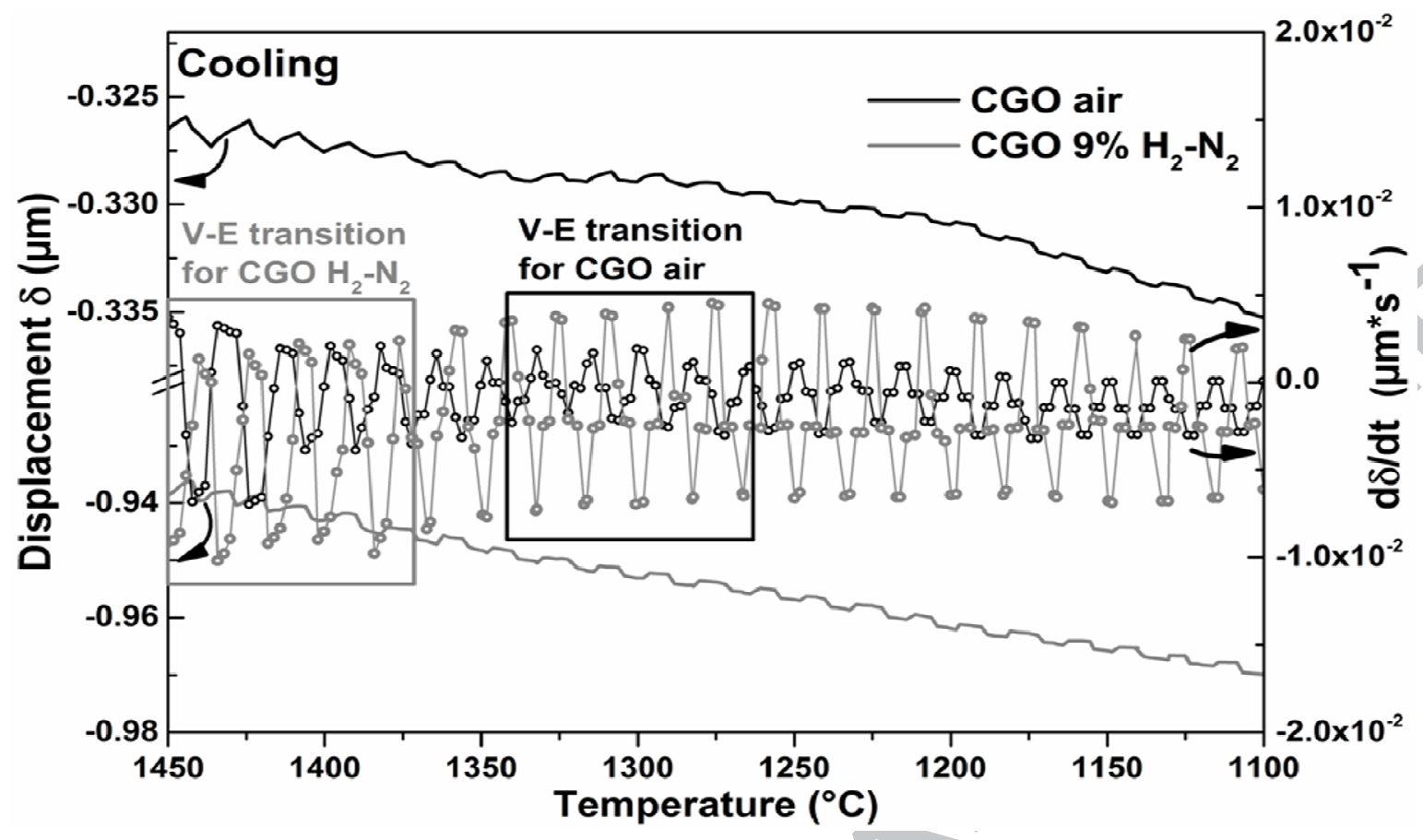

